\section{Abrupt Development of Sarcoidosis with a Prodromal Increase in Plasma Osteopontin in a Patient with Rheumatoid Arthritis During Treatment with Etanercept}

\section{To the Editor:}

Biologic disease-modifying antirheumatic drugs (DMARD) targeting tumor necrosis factor- $\alpha$ (TNF- $\alpha$ ) are very efficacious and the number of patients with rheumatoid arthritis (RA) treated with these drugs is increasing rapidly. Because granulomatous diseases as typified by sarcoidosis are considered to develop in the Th1 cytokine milieu dominated by interferon- $\gamma$ (IFN$\gamma$ ) and TNF- $\alpha$, anti-TNF- $\alpha$ agents have been used for treatment of sarcoidosis. Reports show that infliximab is effective, while etanercept is not, in the treatment of sarcoidosis ${ }^{1,2}$. In contrast, anti-TNF- $\alpha$ agents may have induced sarcoidosis in patients with RA and spondyloarthropathy ${ }^{3-6}$.

The patient we describe had acute onset of sarcoidosis in several organs simultaneously after a long period of remission of RA while receiving etanercept. Based on serum and plasma levels of laboratory indicators related to sarcoidosis, the condition might have developed as quickly as within 1 or 2 months.

A 52-year-old Japanese woman was diagnosed with RA in 1980 and had been treated with several DMARD such as injectable gold salt, sulfasalazine, actarit, methotrexate, and mizoribine with no appreciable effects. Leflunomide was started in 2000 and etanercept $25 \mathrm{mg} /$ week was added in January 2007, increased to $50 \mathrm{mg} /$ week in July 2007. The RA became quiescent under etanercept treatment and the Disease Activity Score 28 fell to 2.22 from 4.17. She had been in clinical remission until a fever of $38.5^{\circ} \mathrm{C}$ and general malaise developed suddenly in March 2008, when she was admitted to hospital.

Evaluation showed fine crackles in both lung fields; they were due to rheumatoid lung and no change was observed in intensity. Superficial lymph nodes were not palpable. Swelling and tenderness were not detected in any joint. Pitting edema was detected bilaterally in the pretibial and pedal regions. The skin on both thighs became pruritic, although no erup- tion was observed on her body. Laboratory data showed the following: white blood cells $6300 / \mu 1$; hemoglobin $11.4 \mathrm{~g} / \mathrm{dl}$; platelets $32.3 \times 10^{4} / \mu 1$; C-reactive protein $10.93 \mathrm{mg} / \mathrm{dl}$; AST $53 \mathrm{mU} / \mathrm{ml}$ (normal < 30); ALT 46 $\mathrm{mU} / \mathrm{ml}(<30)$; ALP $983 \mathrm{mU} / \mathrm{ml}(<330)$; blood urea nitrogen $16 \mathrm{mg} / \mathrm{dl}$; and creatinine $0.40 \mathrm{mg} / \mathrm{dl}$.

Lymph node enlargement in the pulmonary hilar regions and mediastinum was seen on plain chest radiograph and confirmed by computed tomography scan. Sputum culture and polymerase chain reaction investigation were negative for acid-fast bacilli including Mycobacterium tuberculosis. A purified protein derivative skin test was negative. Gallium scintigraphy showed abnormal uptake in the salivary glands, paratracheal region, and right quadriceps muscle (Figure 1A). Fat-saturated T1-enhanced magnetic resonance imaging (MRI) also showed high intensity at the right quadriceps muscle (Figure 1B). Although a skin eruption was not observed, her pruritus became more severe.

Sarcoidosis was one of the differential diagnoses considered, and related data were collected: angiotensin converting enzyme (ACE) $31.5 \mathrm{mU} / \mathrm{ml}$ (normal < 21.4); lysozyme $27.2 \mu \mathrm{g} / \mathrm{ml}(<10.2)$; soluble interleukin 2 receptor (IL-2R) $4830 \mathrm{U} / \mathrm{ml}(<466)$; IFN- $\gamma 0.9 \mathrm{IU} / \mathrm{ml}(<0.1)$; and osteopontin $327 \mathrm{ng} / \mathrm{ml}$ (normal range not determined).

Biopsy specimens were obtained from the liver and skin from the most pruritic area, and both histologies showed noncaseating granulomata with giant cells and lymphocyte infiltration (Figure 1C). The diagnosis of sarcoidosis was based on these histologic findings along with laboratory data. Prednisone $30 \mathrm{mg} /$ day led to rapid symptomatic improvement.

The patient developed sarcoidosis 14 months after the initiation of etanercept for treatment of RA. There are 19 case reports of sarcoidosis developing during anti-TNF therapy (including this one): 10 cases on etanercept, 6 on infliximab, and 3 on adalimumab. At first, the occurrence of sarcoidosis was reported mainly in patients taking etanercept; however, there are an increasing number of cases of sarcoidosis during anti-TNF therapy other than etanercept.

Sarcoidosis is usually diagnosed incidentally based on radiographic

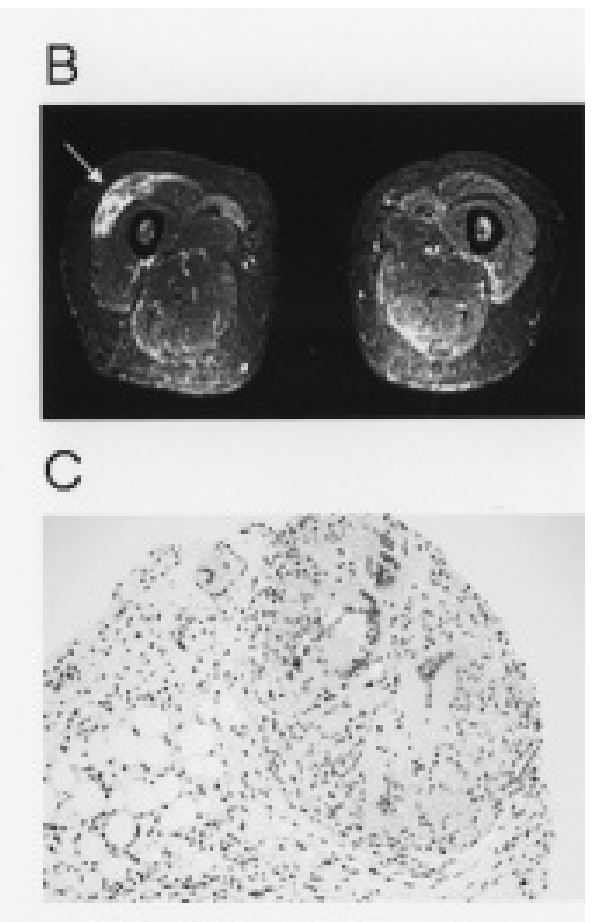

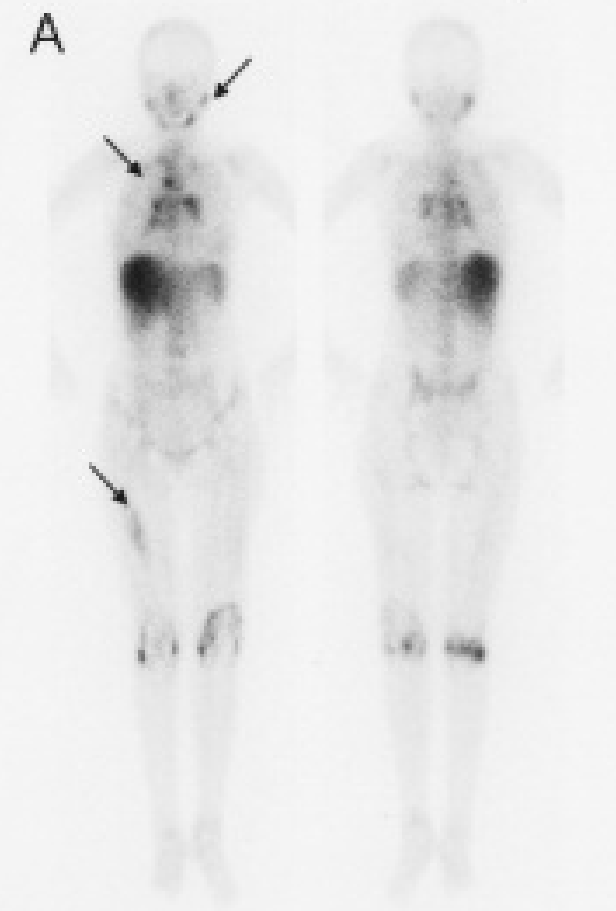

Figure 1. A. Gallium scintigraphy showed abnormal uptake in the salivary glands (upper arrow), hilar and paratracheal lymphnodes (middle arrow), and the right quadriceps muscle (lower arrow). B. Fat-saturated T1-enhanced MRI showed high intensity at the right quadriceps muscle (arrow). C. Biopsy specimen from the skin showed a noncaseating granuloma with multinucleated giant cells 


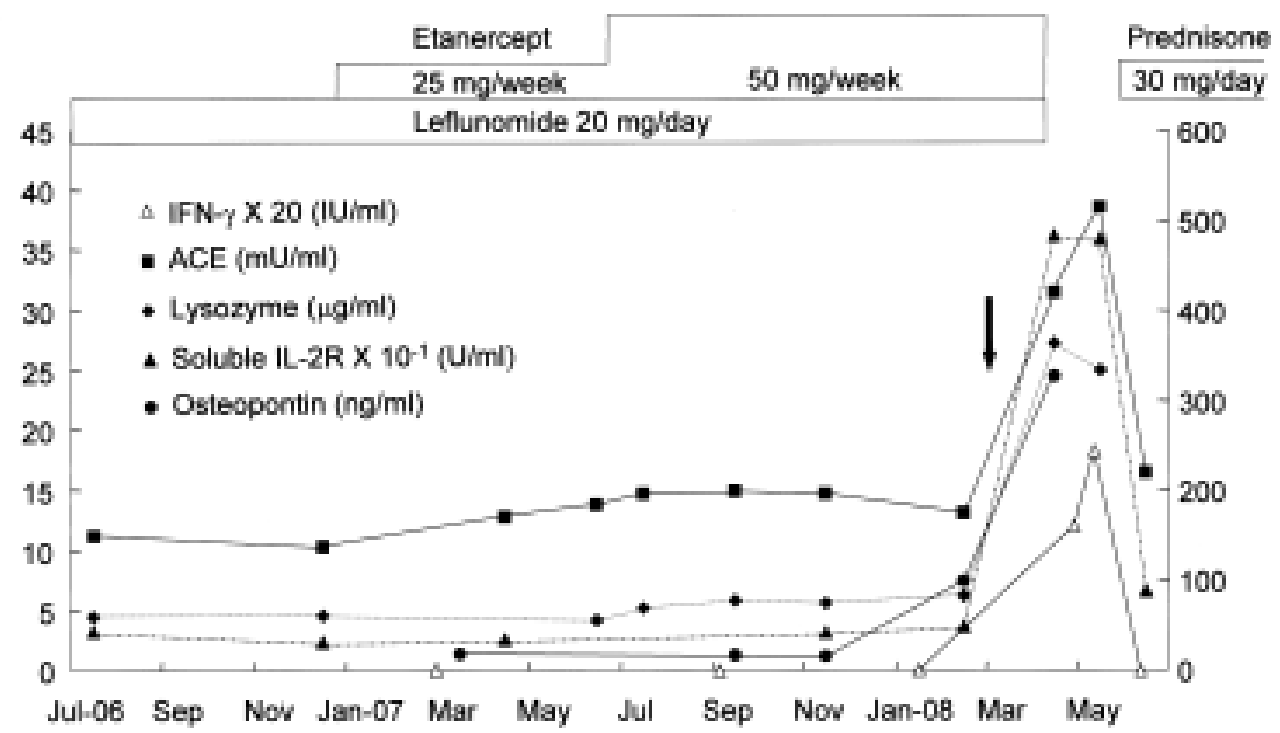

Figure 2. The clinical course of this patient. Arrow indicates date of development of fever and general malaise. Left y-axis shows concentrations of IFN- $\gamma$, ACE, and lysozyme; right y-axis shows soluble IL-1R and osteopontin. ACE: angiotensin-converting enzyme; IL-2R: interleukin 2 receptor; IFN- $\gamma$ : interferon- $\gamma$.

findings and the clinical course is usually indolent, although there are cases with more severe clinical manifestations. Our case showed an acute onset with diffuse organ distribution: salivary glands, muscle, liver, skin, and lung. There were no symptoms, including joint pain, when she presented at the end of February 2008; she was still receiving etanercept along with leflunomide. However, fever and general malaise necessitating hospitalization developed at the end of March. We measured, retrospectively and longitudinally, the serum or plasma levels of ACE, lysozyme, soluble IL-2R, osteopontin, and IFN- $\gamma$, and found that they all increased steeply at the time of admission compared to the previous hospital visits (Figure 2). Longitudinal and repeated measurements of these variables have not previously been reported in patients with sarcoidosis, and accumulation of such data might give us a clue to the pathogenesis of sarcoidosis in the setting of TNF blockade or sarcoidosis in general.

Osteopontin is a noncollagenous matrix protein produced by macrophages and $\mathrm{T}$ lymphocytes that is very important for Th1 response $\mathrm{P}^{7}$. A slight increase in plasma osteopontin level just before steep increases in other variables might deserve attention; osteopontin may portend the development of sarcoidosis and therefore could be important in pathogenicity ${ }^{8}$.

\section{SHINO TAKATORI, MD; YASUYUKI KAMATA, MD; TAKAMASA} MUROSAKI, MD; MASAHIRO IWAMOTO, MD, PhD; SEIJI MINOTA, $\mathrm{MD}$, PhD, Division of Rheumatology and Clinical Immunology, Jichi Medical University, Tochigi, Japan. Address correspondence to Dr. S. Takatori, Division of Rheumatology and Clinical Immunology, Jichi Medical University, Yakushiji 3311-1, Shimotsuke-shi, Tochigi 329-0498, Japan. E-mail: stori@jichi.ac.jp

\section{REFERENCES}

1. Saleh S, Ghodsian S, Yakimova V, Henderson J, Sharma OP Effectiveness of infliximab in treating selected patients with sarcoidosis. Respir Med 2006;100:2053-9.

2. Utz JP, Limper AH, Kalra S, Specks U, Scott JP, Vuk-Pavlovic Z, et al. Etanercept for the treatment of stage II and III progressive pulmonary sarcoidosis. Chest 2003;124:177-85.

3. Peno-Green L, Lluberas G, Kingsley T, Brantley S. Lung injury linked to etanercept therapy. Chest 2002;122:1858-60.

4. Phillips K, Weinblatt M. Granulomatous lung disease occurring during etanercept treatment. Arthritis Rheum 2005;53:618-20.

5. O'Shea FD, Marras TK, Inman RD. Pulmonary sarcoidosis developing during infliximab therapy. Arthritis Rheum 2006;55:978-81.

6. Verschueren K, Van Essche E, Verschueren P, Taelman V, Westhovens R. Development of sarcoidosis in etanercept-treated rheumatoid arthritis patients. Clin Rheumatol 2007;26:1969-71.

7. Koguchi Y, Kawakami K, Uezu K, Fukushima K, Kon S, Maeda $\mathrm{M}$, et al. High plasma osteopontin level and its relationship with interleukin-12-mediated type $1 \mathrm{~T}$ helper cell response in tuberculosis. Am J Respir Crit Care Med 2003;167:1355-9.

8. Carlson I, Tognazzi K, Manseau EJ, Dvorak HF, Brown LF. Osteopontin is strongly expressed by histiocytes in granulomas of diverse etiology. Lab Invest 1997;77:103-8.

J Rheumatol 2010; 37:1; doi:10.3899/jrheum.090647 